\title{
Fatal upper gastrointestinal bleeding caused by a metal biliary stent despite stent shortening with APC
}

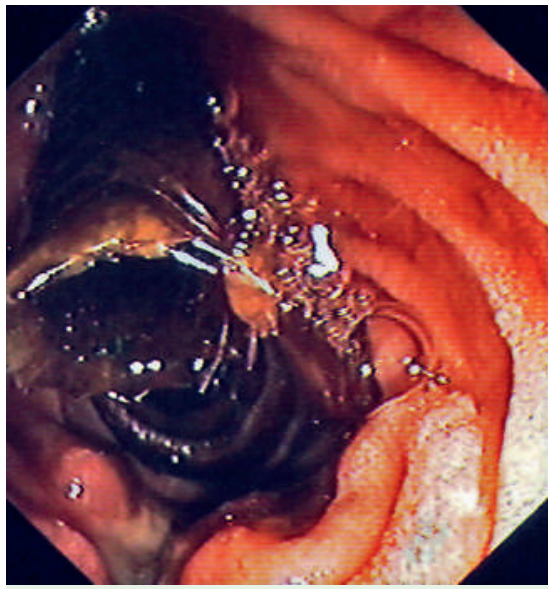

Fig. 1 The stent protruding far from the papilla. A deep ulceration is visible at the duodenal wall opposite the papilla.

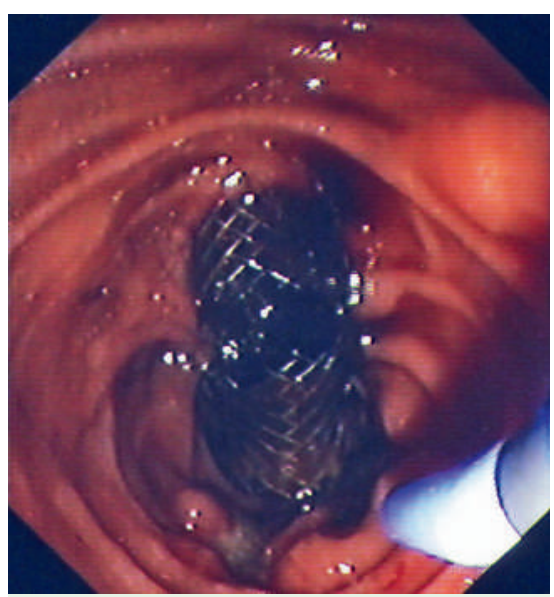

Fig. 2 Half-way through cutting the stent. The ulceration is also visible as is the argon plasma coagulation catheter.

A 75-year-old man presented with hematemesis and melena. He had received an uncovered nitinol self-expanding metal stent (SEMS) 2 months previously for inoperable obstructive hilar cholangiocarcinoma.

Upper endoscopy revealed a normal esophagus, stomach, and duodenal bulb. At the duodenal wall opposite the papilla, a large ulceration with hematin spot ( $\bullet$ Fig. 1) had formed as a result of SEMS impaction. We decided to shorten the stent with argon plasma coagulation (APC). For this procedure we used a duo-

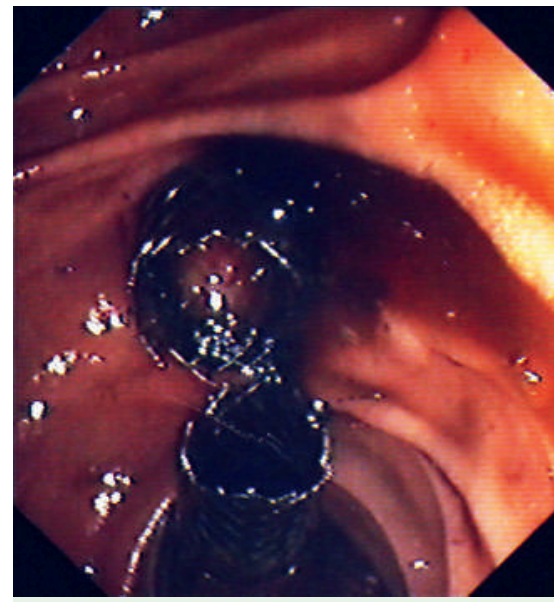

Fig. 3 Final result of cutting the stent. The fragmented piece is afterwards withdrawn along with the scope.

denoscope and an ERBE generator (APC settings: power $80 \mathrm{~W}$, flow rate $1.8 \mathrm{l} / \mathrm{min}$ ute). The section was done circumferentially $1 \mathrm{~cm}$ from the papilla ( $\bullet$ Fig. 2 ), and the stent was shortened by $1.5 \mathrm{~cm}$ (๑ Fig. 3). During his hospitalization the patient was making progress and his hematocrit was stable. He was discharged 4 days later.

He presented again to our hospital the next day with massive hematemesis and melena. At admission he was already in severe oligemic shock and succumbed shortly afterwards.

Ulceration is caused by continuous mechanical irritation of the mucosa opposite the distal end of the stent. Distal migration or malpositioning are the causes of this complication. Furthermore, mucosal ulceration may be promoted by the sharp edges of metal stents [1]. To date, several cases of ulceration and bleeding caused by biliary SEMS have been reported [1 3]. In most cases, bleeding was self-limiting. When indicated, endoscopic hemostasis successfully arrested the bleeding. APC is reported to be a safe, effective, and easy way to reduce stent length [24]. Shortening of the stent, with or without endoscopic hemostasis, was enough to permanently correct the complication in the published cases. Fatal bleeding from SEMS-induced ulceration has never been reported, let alone after endoscopic trimming with APC.

Metal stents are a valuable means of restoring the continuity of the biliary tract. Choosing the correct size and accurate positioning are key factors to reducing complications. Furthermore, metal stents with rounded edges could reduce the risk of ulceration. Finally, longer hospitalization may be advisable when treating SEMS-induced bleeding ulcers.

\section{Endoscopy_UCTN_Code_CPL_1AK_2AD}

\section{S. Dokas ${ }^{1}$, V. Kotsis ${ }^{2}$, G. Milionis ${ }^{2}$ \\ G. Lazaraki ${ }^{1}$, M. Sion ${ }^{2}$}

Endoscopy Department, Papageorgiou General Hospital, Thessaloniki, Greece

2 Third Department of Internal Medicine, Aristotle University of Thessaloniki, Papageorgiou General Hospital,

Thessaloniki, Greece

\section{References}

1 Wai CT, Khor C, Lim SE et al. Post-metallic stent placement bleeding caused by stentinduced ulcers. World J Gastroenterol 2005; 11: 5739- 5741

2 Vanbiervliet G, Piche T, Caroli-Bosc FX et al. Endoscopic argon plasma trimming of biliary and gastrointestinal metallic stents. Endoscopy 2005; 37: 434-438

3 Demarquay JF, Dumas R, Peten EP et al. Argon plasma endoscopic section of biliary metallic prostheses. Endoscopy 2001; 33: 289-290

4 Guda NM, Freeman ML. Endoscopic transection of distally migrated biliary self-expanding metallic stents by using argon plasma coagulation: a report of 2 cases (with video). Gastrointest Endosc 2006; 63: $512-514$

\section{Bibliography}

DOI $10.1055 / s-2007-995713$

Endoscopy 2008; 40: E135

(c) Georg Thieme Verlag KG Stuttgart · New York . ISSN 0013-726X

\section{Corresponding author}

\section{S. Dokas, MD}

Endoscopy Department, Papageorgiou General Hospital, Thessaloniki, Greece

Od. Elyti 20 str.

55132 Kalamaria

Thessaloniki

Greece

altair@med.auth.gr 